\title{
O GEOPROCESSAMENTO COMO SUPORTE AO MANEJO SUSTENTÁVEL DA ERVA-MATE (Ilex paraguariensis A. ST.-HIL.) EM AMBIENTE NATURAL
}

\author{
Paulo Costa de Oliveira Filho*, Gabriela Schmitz Gomes**, Attilio Antonio Disperati*** \\ *Eng. Florestal, Dr., Depto. de Engenharia Florestal, UNICENTRO - paulocostafh@irati.unicentro.com.br \\ ** Eng a . Florestal, M.Sc., Depto. de Engenharia Florestal, UNICENTRO - groella@irati.unicentro.br \\ ***Eng. Florestal, Ph.D., Depto. de Engenharia Florestal, UNICENTRO - disperati@avalon.sul.com.br
}

Recebido para publicação: 28/03/2007 - Aceito para publicação: 31/08/2007

\begin{abstract}
Resumo
O manejo da espécie florestal Ilex paraguariensis A. St.-Hil. (erva-mate) é uma opção de grande potencial econômico para o Sul do país, sobretudo em seu ambiente natural em áreas florestadas. Contudo, exige certos cuidados concernentes às práticas utilizadas em seu manejo, para que haja sustentabilidade da produção ao longo do tempo. Diante disso, um bom planejamento é necessário para que seja realizado um rodízio de colheita e as demais atividades silviculturais, como adensamento de ervais e o enriquecimento com erva-mate em novas áreas com aptidão para tal. $\mathrm{O}$ planejamento das várias operações de manejo florestal conta hoje com uma ferramenta de trabalho cada vez mais promissora: o sistema de informações geográficas (SIG). Este trabalho discute a viabilidade da estruturação de um sistema para o controle das atividades do manejo da erva-mate em ambiente natural, sob dossel.

Palavras-chave: SIG; silvicultura; erva-mate.
\end{abstract}

\begin{abstract}
Geotechnologies as support for the sustainable management of Ilex paraguariensis A. St.-Hil. stands in its natural forest environment. The management of the forest species Ilex paraguariensis St. Hill. is an option of great economic potential in the south of Brazil, specially in its natural forest environment. However it must be adequately conducted in order to keep its sustainable productivity for a long term period. Thus, a suitable planning is necessary for harvesting as rotations well as, for increasing the density of the stands and the enrichment with Ilex paraguariensis of new natural suitable areas. Nowadays, the planning of several management practices can benefit from the use of geographical information systems (GIS). This paper shows the potential of GIS to control forest management practices of the Ilex paraguariensis under canopy stands in natural forest environment. Keywords: GIS; silviculture; Ilex paraguariensis.
\end{abstract}

\section{INTRODUÇÃO}

A sustentabilidade dos ecossistemas florestais é tema recorrente nos últimos anos em todo o mundo. As práticas de gestão dos recursos naturais renováveis deveriam apoiar-se em tecnologias de gestão do espaço geográfico. Processos de suporte técnico à decisão e ao planejamento são vitais para assegurar mecanismos de sustentabilidade dos recursos naturais (GODARD, 2000).

Os sistemas de informações geográficas (SIG) são integradores de diferentes tipos de informação inerentes a uma mesma região ou a um espaço geográfico definido. Dessa forma, proporcionam um conjunto de operações de análise e processamento de dados consideravelmente poderoso.

Atualmente, o crescente interesse pelo cultivo da erva-mate teve contribuição direta do MERCOSUL, cujos países integrantes encontram no consumo da erva-mate um de seus vários pontos em comum, gerando perspectivas positivas para o setor produtivo, particularmente para o Brasil, onde a espécie tem um grande potencial a ser explorado (GORTARI, 1997).

No entanto, devido ao processo de domesticação da cultura da erva-mate visando maiores ganhos de produtividade, retirou-se a espécie de seu hábitat natural no interior da Floresta de Araucária e 
disseminou-se o seu plantio em povoamentos puros a céu aberto. O resultado ao longo do tempo foi desfavorável, pois erveiras expostas aos elevados níveis de luminosidade sofrem alterações nos seus processos metabólicos (KASPARY, 1985; COELHO et al., 2000; RACHWALL et al., 2000), tornandose mais suscetíveis ao ataque de pragas e doenças, além de gerarem um produto com qualidades organolépticas inferiores. Além disso, segundo Petersen et al. (2001), as experiências iniciais usando esse sistema no centro sul do Paraná mostram sua incompatibilidade com as condições locais, principalmente pelo aumento exponencial dos custos de produção.

De acordo com Mazuchowski (2000), toda erveira que esteja em condições de sombreamento parcial por outras espécies arbóreas, ou submetida a níveis de radiação solar parcial devido ao tipo de cobertura, desenvolverá uma matéria-prima que será transformada em produto comercial com padrão de bebida nativa ou sabor mais suave. Segundo esse autor, as demandas industriais para esse tipo de erva acentuaram-se sobremaneira nos últimos anos, sem que tenham sido ajustados mecanismos para estímulo correspondente junto aos produtores de erva-mate.

Ao mesmo tempo em que a erva-mate passa a ser uma ótima opção econômica em floresta natural de araucária sob dossel, inclusive com preços diferenciados, seu manejo necessita de um controle em campo mais complexo, devido à heterogeneidade das condições ambientais, evitando-se colheitas muito intensas ou freqüentes, o que pode reduzir a capacidade auto-sustentável dessa alternativa de manutenção e utilização da floresta.

Os sistemas de informações geográficas (SIG) são integradores de diferentes tipos de informação inerentes a uma mesma região ou a um espaço geográfico definido. Exemplos de informação inerentes a uma mesma região podem advir do mapeamento de produtos de sensores remotos (fotografias aéreas ou imagens satelitárias), de levantamentos cadastrais elaborados em campo e de informações genéricas disponíveis sobre o(s) tema(s) em questão. São exemplos específicos de espaço geográfico florestal: um talhão de reflorestamento, um fragmento de mata nativo, uma propriedade ou mesmo áreas nativas de ervais em uma propriedade. Dessa forma, pela quantidade de informações disponíveis, os SIGs proporcionam um conjunto de operações de análise e processamento de dados consideravelmente poderoso.

\section{Objetivos gerais e específicos}

Este trabalho, baseado em dados reais disponíveis, se propõe a discutir aspectos referentes à elaboração e à utilização de um SIG como suporte às atividades que envolvem o manejo da erva-mate (Ilex paraguariensis A. St.-Hil.) em ambiente natural sob dossel.

Os objetivos específicos do trabalho são:

a) caracterizar a espécie erva-mate e as suas práticas de manejo em ambiente natural e quando possível particularizar para o estado do Paraná;

b) discutir a elaboração e a utilização de um SIG, utilizando dados disponíveis, como suporte às atividades que envolvem o manejo da erva-mate em ambiente natural sob dossel.

\section{Caracterização da espécie e das práticas de manejo da erva-mate em ambiente natural}

A erva-mate pertence à família Aquifoliaceae, sendo característica da Floresta Ombrófila Mista (Floresta com Araucária), sempre em associações nitidamente evoluídas com o pinheiro-do-paraná (Araucaria angustifolia) (CARVALHO, 2003).

Considerada uma das riquezas do sub-bosque da Floresta com Araucária, a erva-mate apresenta um grande potencial econômico, além de representar uma ótima opção para a condução do manejo sustentado da floresta em uma perspectiva de uso múltiplo dos recursos naturais. A figura 1 ilustra uma floresta natural aberta, em que, devido ao espaçamento natural entre as árvores, a luz pode atingir os estratos inferiores e permitir o desenvolvimento satisfatório de exemplares de erva-mate de exploração sustentada.

Segundo Conto (2000), a distribuição de ervais nativos pela Região Sul do Brasil ocorre da seguinte forma: 47,5\% no Paraná, 28,3\% em Santa Catarina e 24,2\% no Rio Grande do Sul. O Paraná é responsável por $56 \%$ da produção total, seguido por Santa Catarina com 33,9\% e Rio Grande do Sul com 10,1\%.

A diversidade existente nos tipos de ervais, e ainda a pouca sistematização de produção, estão relacionadas, em termos de escala cultivo/exploração, às práticas adotadas tradicionalmente, as quais são comuns tanto entre os pequenos como entre os grandes produtores (PICHETH, 2001).

De acordo com Andrade (2002), o sistema de produção, a área dos ervais, a produtividade e a qualidade da matéria-prima são fatores que indicam o perfil dos produtores, sendo que o sistema de produção tem forte influência sobre os retornos econômicos e/ou ambientais da propriedade. 


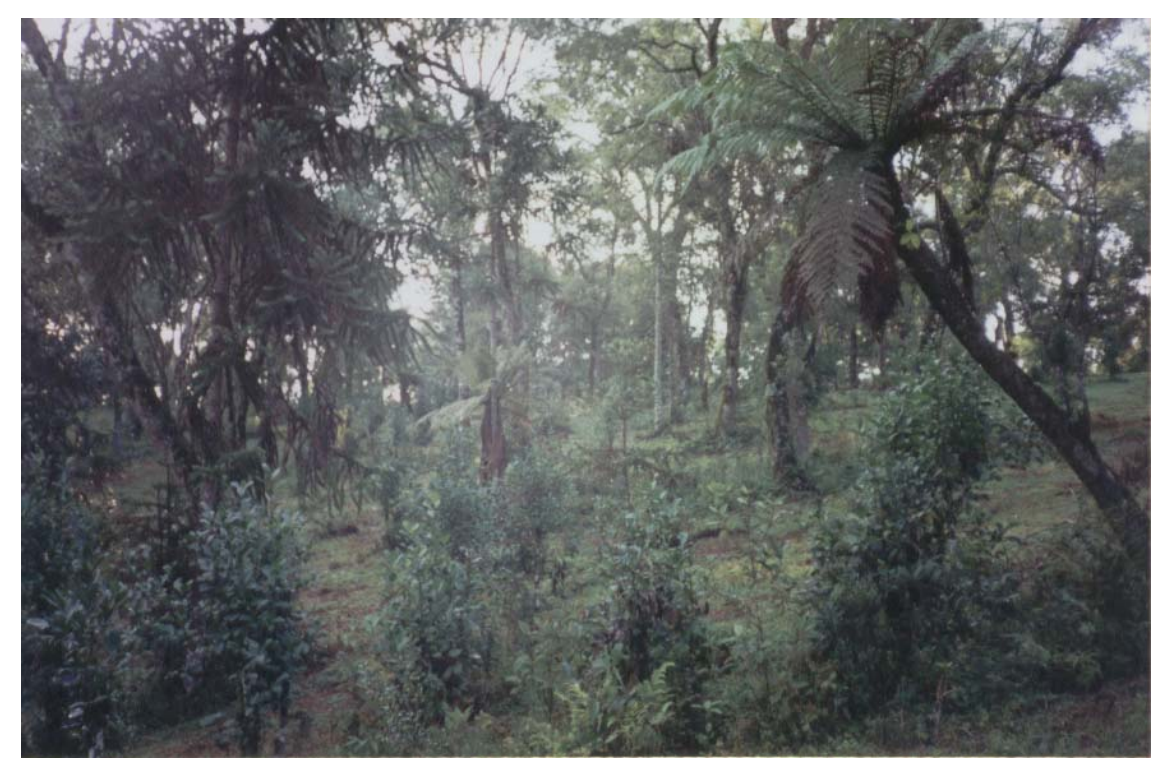

Figura 1. Aspecto de um erval nativo em área de Floresta com Araucária no município de Turvo (PR). Figure 1. Natural stand of "erva-mate" in an Araucarian forest in Turvo county - Paraná State.

Em linhas gerais, no Paraná pode-se dividir a ocorrência dos ervais nativos em três situações: a) Áreas pertencentes a empresas florestais

Podem ser empresas cuja atividade principal é a produção de erva-mate ou em que ela pode ser apenas uma atividade extra dentro de áreas tidas como de conservação ambiental. Neste caso, a mão-deobra pode ser terceirizada através de empreiteiras ou realizada pelos próprios empregados da empresa em época de entressafra das demais atividades. Conto (2000), a partir de dados do IBGE, verificou que 58\% da produção de erva nativa no Paraná são provenientes de estabelecimentos classificados como de silvicultura e exploração florestal.

b) Áreas pertencentes a pequenos e médios proprietários rurais

Embora hoje sua importância econômica relativa seja menor para os pequenos agricultores, a extração da erva-mate segue sendo um fator estabilizador da renda familiar, já que é menos vulnerável às oscilações de clima e dos mercados que outros cultivos tradicionais, como feijão e milho (PETERSEN et al., 2001). Inclusive, segundo os autores, foi o reconhecimento dessa função estratégica que fez com que os agricultores preservassem grandes áreas de floresta nativa em seus agroecossistemas. Muitas indústrias ervateiras trabalham em regime de parceria com esses produtores, comprando a erva verde no pé (a colheita é de responsabilidade da ervateira) ou após a colheita. Os proprietários podem entregar a erva-mate em folha bruta verde para a indústria ou realizar um pré-beneficiamento (cancheamento), entregando a folha já seca.

c) Áreas pertencentes ao Sistema Faxinal

Parte significativa dos ervais nativos sob sombreamento encontra-se em áreas caracterizadas como "Sistema Faxinal", cuja origem histórica está intimamente ligada à atividade ervateira, e que hoje, conforme dados preliminares obtidos por Marques (2005), cobrem uma superfície florestada de cerca de 16.000 hectares. É um sistema tradicional de uso da terra próprio da região da Floresta com Araucária no Centro-Sul do Paraná. Fundamenta-se basicamente na produção animal coletiva à solta, na policultura alimentar de subsistência para consumo e comercialização e no extrativismo florestal de baixo impacto, através do manejo de erva-mate e outras espécies nativas, conforme regulamenta o Decreto Estadual $n^{\circ}$ 3.446/97. Nessas comunidades, a atividade ervateira reveste-se de especial importância, dado o grau de precariedade econômica em que vive a população residente. A renda vinculada à erva-mate vem da própria venda do produto, no caso do dono das erveiras, ou da venda de serviço para a colheita, geralmente realizada pelos próprios moradores locais. Ao mesmo tempo, por se tratar de um sistema intrinsecamente relacionado à Floresta com Araucária, possui grande potencial na produção de erva-mate sombreada, podendo inclusive receber certificação sob aspectos ambientais e sociais, bastando para tanto ter essa atividade devidamente fomentada em termos sustentáveis. 
Como prática geral nos ervais nativos nas três situações descritas anteriormente, para favorecer o desenvolvimento das plantas e melhor aproveitamento da mão-de-obra e rendimento, há necessidade de tratos culturais e silviculturais, como descreve a seguir Andrade (2002):

- limpeza: roçada da vegetação de menor porte, que facilita a movimentação do produtor dentro do erval para a colheita, diminuindo a concorrência das erveiras com outras plantas. A capina e a roçada propiciam também a regeneração de novas mudas;

- raleamento: retirada, se necessário, de plantas de erva-mate que estejam muito próximas e de espécies arbóreas que reduzam muito a luz no interior da floresta;

- adensamento: plantio de erva-mate nas clareiras existentes para aumentar a produção do erval e/ou plantio de mudas de outras espécies florestais, que diversificam o ambiente e podem produzir lenha ou outros produtos;

- recuperação de plantas decadentes: decepam-se as erveiras velhas improdutivas, ou, ainda, se faz o rebaixamento das plantas quando muito altas, por dificultar a colheita.

Gomes e Domingos (2006) registraram as práticas silviculturais de adensamento de ervais nativos executadas no centro-sul do Paraná, verificando que se iniciam com a roçada do estrato herbáceo e/ou na aplicação de herbicida, retirada de troncos caídos e poda das árvores indesejáveis. A segunda etapa envolve o coveamento ou abertura de linhas, a adubação e plantio das mudas de erva-mate, ainda fazendo parte das práticas o replantio, o coroamento das mudas e o combate às formigas.

\section{A sustentabilidade do manejo da erva-mate}

É reconhecidamente necessária a definição de um período entre colheitas, bem como da intensidade da colheita, para que as plantas tenham plenas condições de manter a produção de massa foliar dentro de um patamar desejável (OLIVEIRA-FILHO e PICHETH, 2004).

Segundo a Instrução Normativa do IBAMA n ${ }^{\circ} 118-\mathrm{N}$, de 1992, a exploração da erva-mate deve obedecer à adoção de técnicas de condução e manejo, destinadas a maximizar a produção da massa foliar e minimizar a ocorrência de prováveis danos aos ervais, visando compatibilizar o rendimento sustentado com a preservação da espécie.

Há produtores e indústrias que praticam podas em qualquer época do ano, mas, em geral, segundo Andrade (2002), dois períodos são caracterizados: 1) safra: ocorre de maio a setembro, com maior concentração nos meses de junho a agosto. Nesse período, a planta está em repouso fisiológico e não sofre muito com as podas; 2) safrinha: ocorre de dezembro a fevereiro. É pouco praticada, pois as novas brotações podem ser afetadas por geadas fora de época ou insolação. É nesse período que as indústrias aproveitam para renovar seus estoques.

Apesar da importância de um controle eficiente para dar subsídios ao planejamento das operações que envolvem o manejo da erva-mate, é muito comum na atividade de colheita de erva-mate a terceirização de serviços e a contratação de empreiteiros. Essa pode ser uma solução para os problemas de mão-de-obra, porém, a falta de organização e controle dessas operações pela empresa contratante pode vir a provocar situações em que a seleção de áreas para exploração ocorre ao acaso ou então quando a atividade é realizada somente nos locais mais próximos às estradas. Em ambos os casos, não há qualquer planejamento, o que acarreta prejuízos ao erval, devido à retirada excessiva de produto em determinadas áreas em detrimento de outras.

\section{O SIG no gerenciamento dos ervais em ambiente natural}

As transformações que ocorrem no contexto do espaço rural como conseqüência da dinâmica do processo de ocupação e exaustão ambiental que caracteriza o modelo mais usual de exploração econômica da erva-mate são antagônicas aos interesses discutidos e publicados na Agenda 21, resultado da Conferência das Nações Unidas sobre o Meio Ambiente e Desenvolvimento, celebrada em 1992. Em seu capítulo 35, A Ciência para o Desenvolvimento Sustentável, é abordado o papel das ciências no apoio ao manejo prudente do meio ambiente como meio de implementação para se atingir o manejo sustentável dos recursos ambientais. Algumas das ferramentas mencionadas são as tecnologias de informação que auxiliem na gestão do espaço geográfico. A expressão "gestão do espaço geográfico" inclui naturalmente todas as operações necessárias ao bom gerenciamento ou manejo de uma área, tais como mapeamento e medição (topografia e sensoriamento remoto para estudos de uso e ocupação do solo), cadastro para que os dados sejam sempre atuais e confiáveis e a utilização de bancos de dados espaciais (SIG), para permitir 
consultas e análises com resultado já espacializado (na forma de mapas).

O sistema de informações geográficas consiste em um caso particular de sistema de informações, no qual o banco de dados contém dados associados a entidades distribuídas espacialmente, as quais podem ser representadas e definidas no espaço como pontos, linhas ou polígonos (áreas). Oliveira-Filho (2001) implementou modelos de dados distintos com o uso de sistemas de informações geográficas para integrar o modelo administrativo rural/florestal de uma empresa. Nesse mesmo trabalho, essa tecnologia foi utilizada para integrar dados para o manejo da erva-mate em ambiente natural sob dossel.

Ferrari (1997) acredita no uso de sistemas de informações geográficas mais leves se comparados a bancos de dados mais complexos, e com objetivos específicos. Seguindo a idéia desse mesmo autor, pode-se, por exemplo, elaborar modelos de dados espaciais com aplicações direcionadas para a administração rural ou mesmo para manejo de espécies plantadas ou nativas, que é o caso na questão dos ervais.

\section{METODOLOGIA}

\section{Área de estudo}

A empresa cujos dados foram utilizados neste trabalho possui sede no município de Pinhão, estado do Paraná, e apresenta propriedades dispersamente distribuídas entre a sede da empresa e as localidades de Colônia Vitória, Pedro Lustosa, Faxinal do Céu e Paredão, compreendidas entre as coordenadas $25^{\circ} 59^{\prime} 55^{\prime \prime}$ e $25^{\circ} 25^{\prime} 56^{\prime \prime}$ de latitude Sul e 56 $00^{\circ} 06^{\prime \prime}$ e $55^{\circ} 15^{\prime} 13^{\prime \prime}$ de longitude Oeste.

\section{Procedimentos metodológicos}

Para a elaboração do SIG, foi feita a compilação das informações do mapeamento, cadastro e de manejo florestais, que são fundamentais na implementação e na operacionalidade do sistema. Todo o trabalho foi executado utilizando-se o software SPRING (Sistema de Processamento de Informações Georreferenciadas), versão 4.2, do INPE (Instituto Nacional de Pesquisas Espaciais).

A figura 2 ilustra o fluxograma de um SIG para o gerenciamento dos plantios de erva-mate em ambiente natural, cujos detalhes serão especificados a seguir.

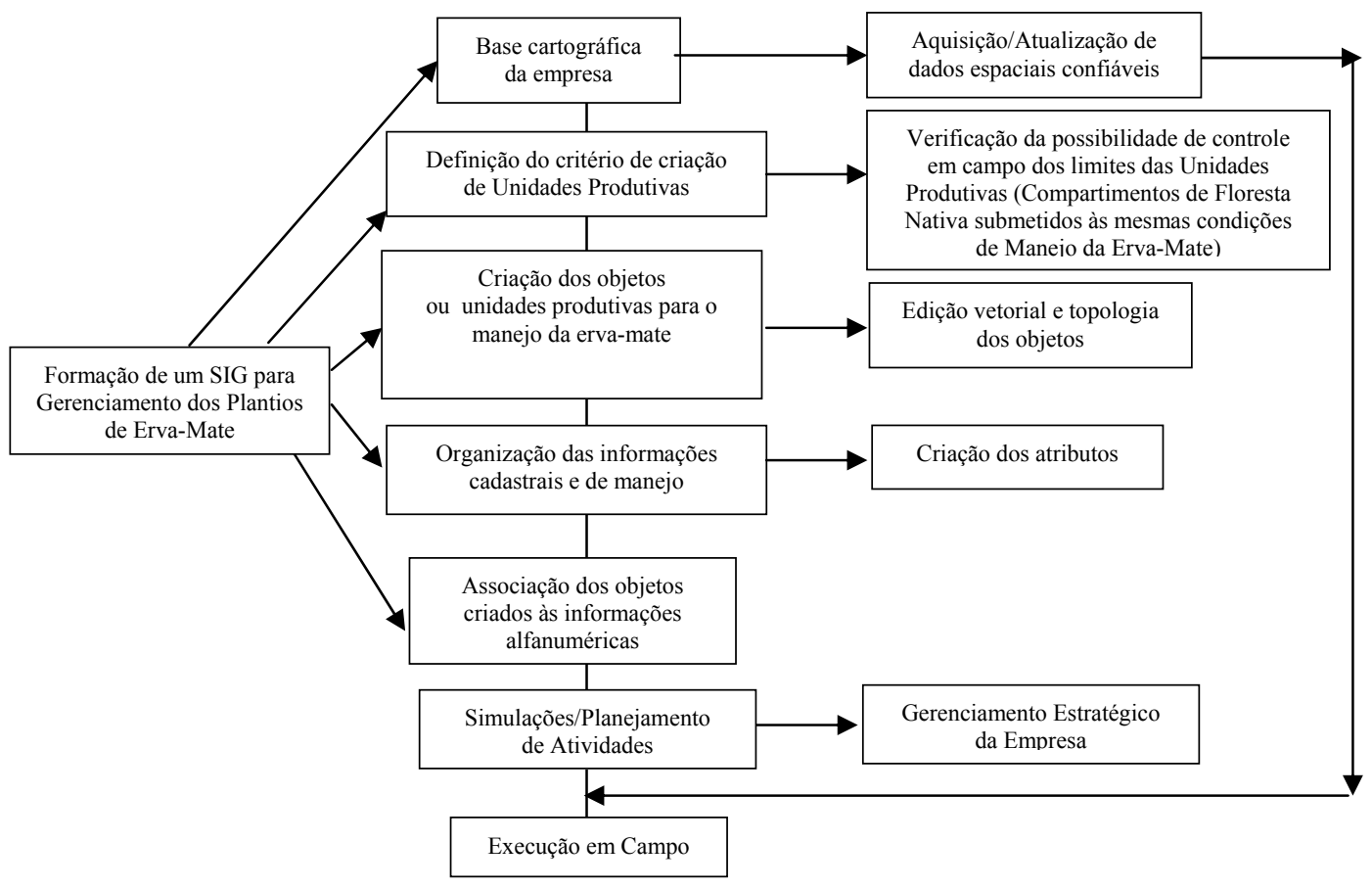

Figura 2. Procedimentos utilizados para a elaboração do modelo de dados do Sistema de Informações Geográficas.

Figure 2. Methodological approach for the elaboration of the Geographic Information System. 
A base cartográfica utilizada no mapeamento florestal geralmente advém de mapas topográficos existentes e constitui-se em uma série de informações, como rede hidrográfica, estradas, curvas de nível, rede de coordenadas geográficas e acidentes naturais, dentre outras. Sobre tal base cartográfica será inserido o resultado da interpretação dos produtos de sensores remotos utilizados, como fotografias aéreas e/ou imagens satelitárias. Entretanto, para a questão dos ervais, os referidos produtos servirão apenas para delimitar os fragmentos florestais existentes nos locais considerados. Como detalhado anteriormente, os ervais, por ocuparem os estratos inferiores da floresta, dificilmente serão caracterizados nos produtos dos sensores remotos. O delineamento das Unidades Produtivas (Compartimentos de Floresta Nativa submetidos às mesmas condições de Manejo da Erva-Mate) deverá ser feito através de levantamentos de campo e utilizando as técnicas modernas de GPS/DGPS ou de topografia.

É fato sobejamente conhecido a dificuldade de captar os sinais GPS debaixo de cobertura arbórea densa. Desse modo, dependendo das condições dos ervais e da floresta, a utilização da técnica de GPS/DGPS poderá não ser viável. Nessa situação, é indicada a utilização das técnicas topográficas usando teodolito e trena ou estação total, ou mesmo levantamentos expeditos com bússola e trena. Além do mapeamento em campo das diversas Unidades Produtivas, será necessário o detalhamento de informações sobre cada uma delas, através da criação de atributos associados às práticas silviculturais e de manejo dos ervais, além de condições naturais do sítio. Nessa concepção, podem-se utilizar entidades geográficas poligonais para representar unidades produtivas ou compartimentos submetidos às mesmas condições de manejo (talhões) e associá-las aos respectivos dados ou atributos, caracterizando-os, conforme o caso, no tempo e no espaço.

Desse modo, como dados ou atributos, verificados através de levantamentos expeditos em campo ou oriundos de planejamentos estratégicos, pode-se prever:

a) Práticas silviculturais e de manejo, tais como operações de adensamento, enriquecimento, raleamento, colheita, limpeza do sub-bosque, rebaixamento e decepa de erveiras etc.

b) Condições do sítio, tais como tipo de solo, cobertura arbórea, composição do estrato herbáceo, densidade do erval, luminosidade sob dossel etc.

c) Outros, tais como destino da produção, empreiteira responsável, presença de gado, procedência das mudas implantadas etc.

Desse modo, como dados ou atributos, verificados através de levantamentos expeditos em campo ou oriundos de planejamentos estratégicos, pode-se prever:

a) Práticas silviculturais e de manejo, tais como operações de adensamento, enriquecimento, raleamento, colheita, limpeza do sub-bosque, rebaixamento e decepa de erveiras etc.

b) Condições do sítio, tais como tipo de solo, cobertura arbórea, composição do estrato herbáceo, densidade do erval, luminosidade sob dossel etc.

c) Outros, tais como destino da produção, empreiteira responsável, presença de gado, procedência das mudas implantadas etc.

A partir da elaboração de uma base cartográfica temática, neste trabalho buscou-se fazer simulações de operações normalmente executadas na atividade ervateira, tendo em vista o controle espacial das intervenções necessárias, prevendo-se o manejo sustentável da espécie e a previsão de colheitas futuras.

\section{RESULTADOS E DISCUSSÃO} SPRING.

As figuras a seguir ilustram a potencialidade das simulações apresentadas na tela do software

A figura 3 apresenta a tela do aplicativo exibindo o resultado de uma consulta elaborada com informações alimentadas no banco de dados sobre a temática "densidade de erva-mate" nas unidades produtivas. Como a informação "Densidade de Erva-Mate" está no banco de dados e está, portanto, associada aos talhões, os quais foram definidos como geo-objetos, essa consulta, através de uma simples operação de agrupamento, resultou em um mapa informativo para o planejamento das áreas ou talhões em que a densidade dessa espécie pode ser aumentada nos próximos anos, ou mesmo, para definição dos próximos talhões para colheita. 


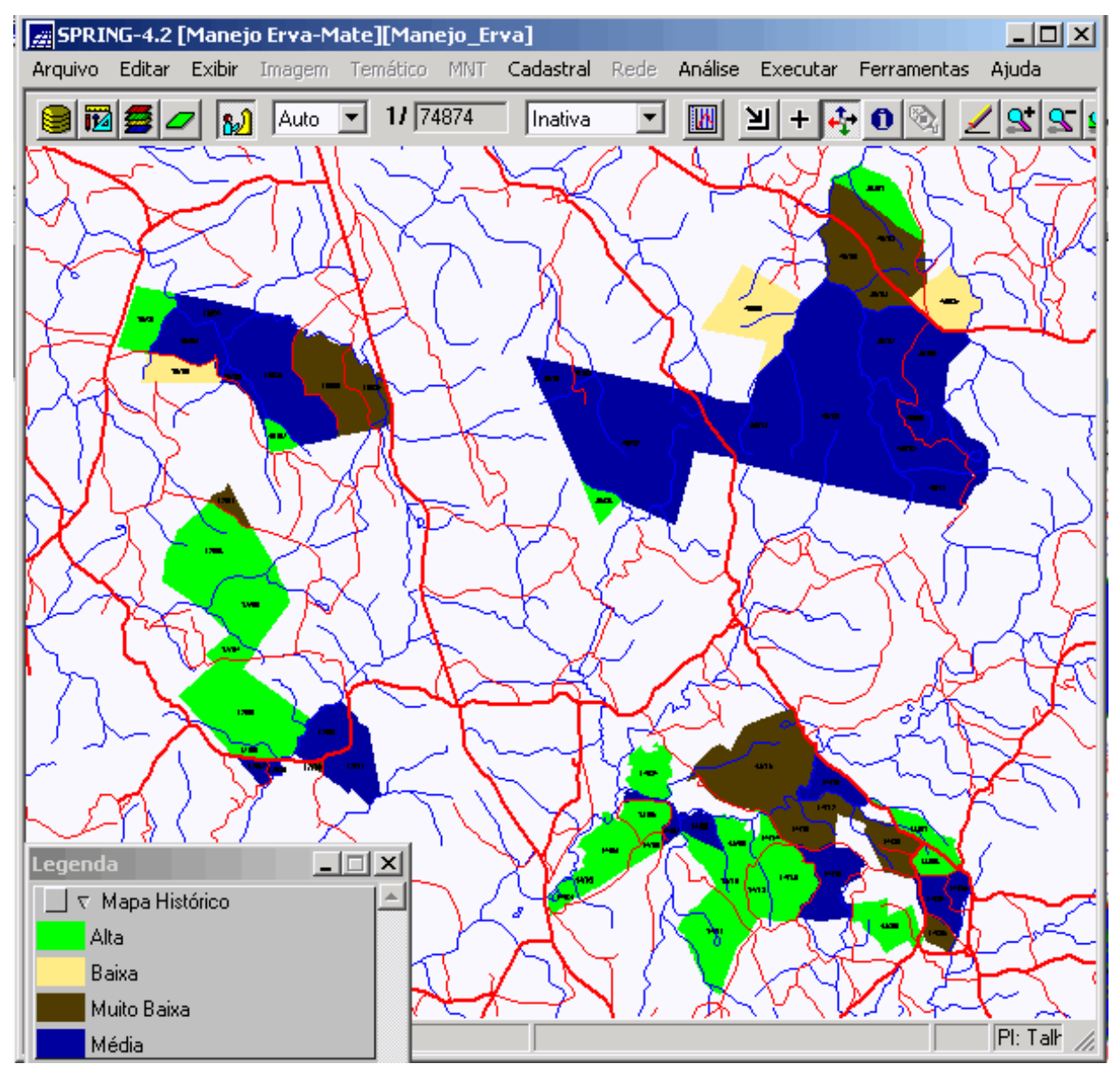

Figura 3. Tela de um aplicativo de SIG exibindo resultado espacial das diferentes Unidades Produtivas de erva-mate em função das diferentes densidades de erva-mate.

Figure 3. Screen of an applicatory one of GIS showing a map of the different Productive Units of "ervamate" considering its different densities.

A figura 4 , da mesma forma que a figura 3 , exibe um produto temático obtido através de uma função de agrupamento de objetos, desta vez utilizando informações sobre operações de manejo a serem realizadas em diferentes unidades produtivas de erva-mate em um prazo de 5 anos. Esse mapa temático é uma contribuição importante no contexto de planejamento de atividades de uma empresa, pois, em função das operações silviculturais já realizadas em cada unidade produtiva, novas atividades podem ser programadas.

A figura 5 mostra uma consulta ao sistema sobre as possíveis unidades produtivas que estarão aptas para colheita de erva-mate no ano de 2008.

Já a figura 6 mostra as áreas ou unidades produtivas que estão previstas para um adensamento de erva-mate, em função de não apresentarem uma densidade razoável dessa espécie podendo ser otimizadas.

Assim como essas consultas foram elaboradas no sistema implementado, em função da riqueza e quantidade de informações disponíveis, muitas outras simulações poderão ser realizadas atendendo a inúmeras questões que ocorrem na prática.

Dessa forma, os sistemas de informações geográficas, como integradores de dados espaciais (cartográficos) e atributos de manejo, podem auxiliar na definição da rotação da colheita e no prognóstico da produção da erva-mate, bem como nas demais atividades previstas no planejamento, facilitando as operações de ordenamento, no sentido de torná-las sustentáveis ecológica e economicamente. 


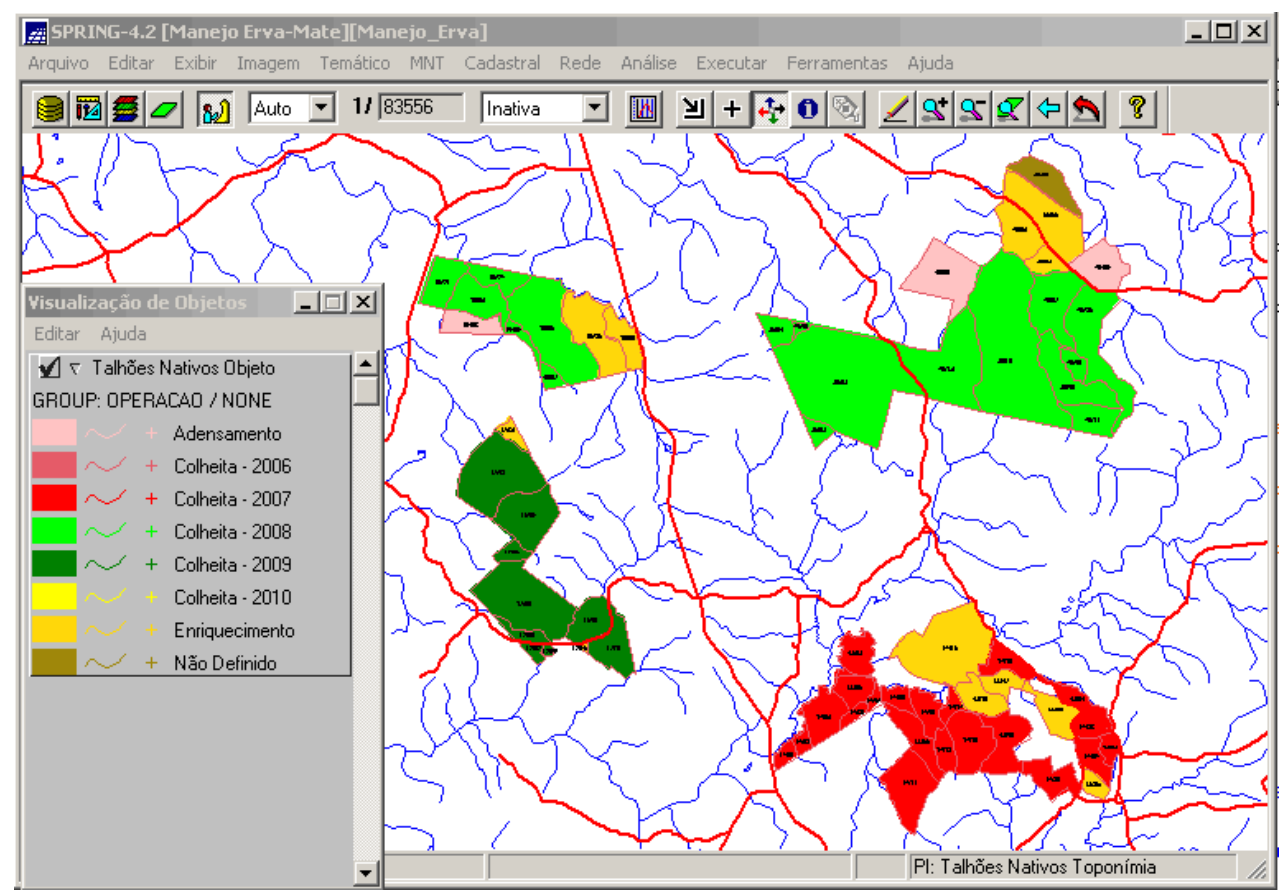

Figura 4. Tela de um aplicativo de SIG exibindo mapa de práticas silviculturais e de manejo a serem aplicadas em diferentes unidades produtivas.

Figure 4. Screen of an applicatory one of GIS showing a map of silvicultural practices to be applied in different productive units.

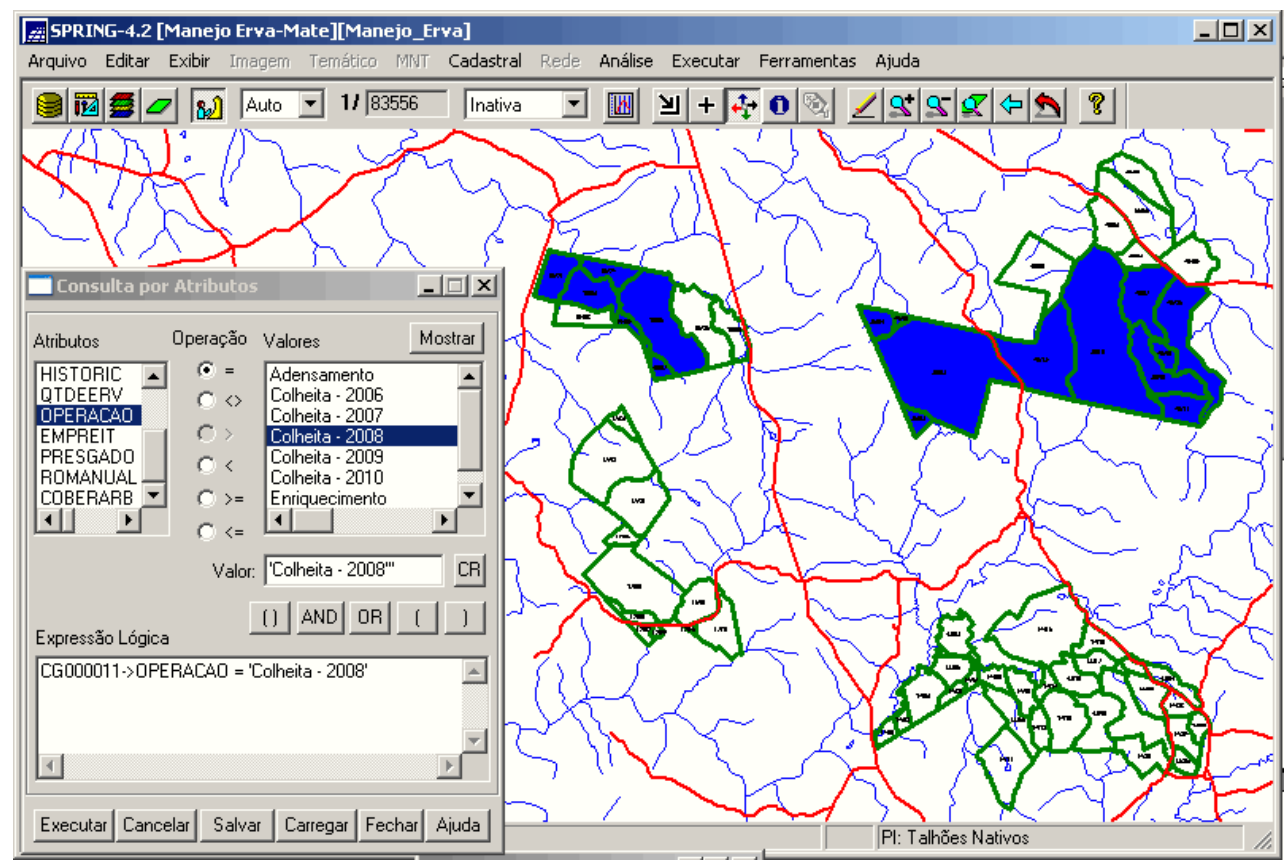

Figura 5. Tela de um aplicativo de SIG exibindo resultados da consulta sobre as unidades produtivas disponíveis para colheita em 2008.

Figure 5. Screen of a applicatory one of GIS showing a query results on available productive units for harvesting in 2008. 


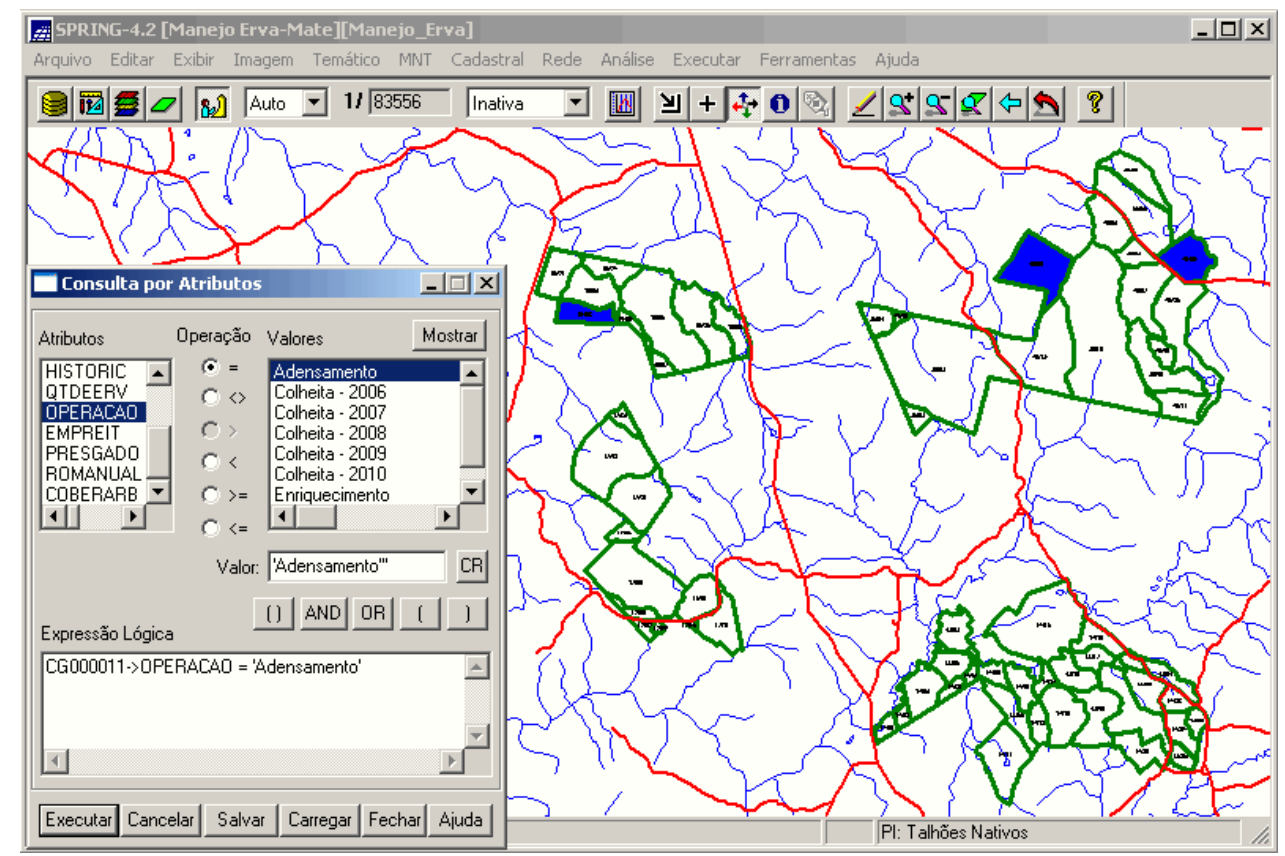

Figura 6. Tela de um aplicativo de SIG exibindo resultados da consulta sobre as unidades produtivas para adensamento da erva-mate.

Figure 6. Screen of a applicatory one of GIS showing query results on available productive units for density increasing of erva-mate.

\section{CONSIDERAÇÕES FINAIS}

Como pode ser observado nas simulações apresentadas, a utilização do SIG mostrou-se como uma ferramenta de controle e atualização de informações relativas ao manejo que pode ser aplicada tanto em áreas pertencentes a empresas florestais quanto em áreas particulares ou em Sistema Faxinal, de acordo com suas peculiaridades.

Novos projetos similares poderão implementar modelos de dados ainda mais complexos, que contenham aspectos econômicos e/ou silviculturais que possam enriquecer, conforme suas especificidades, o sistema de informações geográficas gerado para essa finalidade, assim como testar na prática a metodologia apresentada neste trabalho.

\section{REFERÊNCIAS}

ANDRADE, F. M. de. Exploração, manejo e potencial socioeconômico da erva-mate. IN: SIMÕES, L. L.; LINO, C. F. (Org.). Sustentável Mata Atlântica: a exploração de seus recursos florestais. São Paulo: SENAC, 2002. p. 19-34.

CARVALHO, P. E. R. Espécies arbóreas brasileiras. Colombo: EMBRAPA Florestas, 2003. 1039 p.

COELHO, G. C.; RACHWAL, M.; SCHNORRENBERGER, E.; SCHENKEL, E. P. Efeito do sombreamento sobre a sobrevivência, morfologia e química da erva-mate. In: CONGRESSO SULAMERICANO DA ERVA-MATE, 2.; REUNIÃO TÉCNICA DA ERVA-MATE, 3., 2000, Encantado, RS. Anais... Porto Alegre: Universidade Federal do Rio Grande do Sul. Fundação Estadual de Pesquisa Agropecuária, 2000. p. 396-399.

CONFERÊNCIA DAS NAÇÕES UNIDAS SOBRE MEIO AMBIENTE E DESENVOLVIMENTO 1992, Rio de Janeiro. A Agenda 21. Curitiba: IPARDES, 2001. 260 p.

CONTO, A. J. A estrutura da produção de erva-mate na Região Sul. In: II CONGRESSO SUL-

FLORESTA, Curitiba, PR, v. 38, n. 1, jan./mar. 2008. 
AMERICANO DA ERVA-MATE, 2.; REUNIÃO TÉCNICA DA ERVA-MATE, 3., Encantado, RS. Anais... Porto Alegre: Universidade Federal do Rio Grande do Sul. Fundação Estadual de Pesquisa Agropecuária, 2000. p. 210-214.

FERRARI, R. Viagem ao SIG: planejamento estratégico, viabilização, implantação e gerenciamento de sistemas de informação geográfica. Curitiba: Sagres, 1997.

GODARD, O. A gestão integrada dos recursos naturais e do meio ambiente: conceitos, instituições e desafios de legitimação. In: VIEIRA,P. F.; WEBER, J. (Org.). Gestão de recursos naturais renováveis e desenvolvimento: novos desafios para a pesquisa ambiental. 2. ed. São Paulo: Cortez, 2000.

GOMES, G. S.; DOMINGOS, D. M. Práticas silviculturais de adensamento de remanescentes florestais com erva-mate (Ilex paraguariensis) no Centro-Sul do Paraná, Brasil. In: SEMINÁRIO DE PESQUISA, 18., Irati-PR. Anais... Irati: Universidade Estadual do Centro-Oeste do Paraná, 2006. 1 CD Room.

GORTARI, J. El Mercosur y la economia yerbatera. In: CONGRESSO SUL-AMERICANO DA ERVAMATE, 1.; REUNIÃO TÉCNICA DO CONE SUL SOBRE A CULTURA DA ERVA-MATE, 2., Curitiba. Anais... Colombo: EMBRAPA-CNPF, 1997.

KASPARY, R. Efeitos de diferentes graus de sombreamento sobre o desenvolvimento e trocas gasosas de plantas jovens de erva-mate (Ilex paraguariensis). 200 p. Dissertação (Mestrado) Universidade Federal do Rio Grande do Sul, Porto Alegre, 1985.

MARQUES, C. L. G. Levantamento preliminar sobre o Sistema Faxinal no Estado do Paraná: Relatório de Consultoria Técnica. Curitiba: IAP, 2005. 192 p. Mimeografado.

MAZUCHOWSKI, J. Z. Alternativas para o incremento da produtividade de ervais nativos. In: CONGRESSO SUL-AMERICANO DA ERVA-MATE, 2.; REUNIÃO TÉCNICA DA ERVA-MATE, 3., Encantado, RS. Anais... Porto Alegre: Universidade Federal do Rio Grande do Sul. Fundação Estadual de Pesquisa Agropecuária, 2000. p. 6-9.

OLIVEIRA-FILHO, P. C.; PICHETH, J. A. T. F. Definição de sub-unidades de manejo da erva-mate para a criação de geo-objetos poligonais em um sistema de informações geográficas. Revista de Ciências Exatas e Naturais, Guarapuava, v. 6, n. 2, p. 223-231, jul/dez 2004.

OLIVEIRA-FILHO, P. C. Implementação de sistemas de informação geográfica para a gestão da empresa florestal. 152 f. Tese (Doutorado em Ciências Florestais) - Setor de Ciências Agrárias, Universidade Federal do Paraná, Curitiba, 2001.

PETERSEN, P.; TARDIN, J. M.; MAROCHI, F. 2001. Del manejo extractivo al regenerativo, el caso de los bosques de araucaria en el Paraná. Lima, Peru. LEISA, v. 16/3, 4 p. Disponível em: $<\mathrm{http}$ //www.leisa-al.org.pe/anteriores/163/08.html> Acesso em: 19/07/2006.

PICHETH, J. A. T. F. Eficácia na produção de biomassa da erva-mate estabelecida com mudas produzidas de estacas e de sementes. Tese (Doutorado em Agronomia) - Setor de Ciências Agrárias, Universidade Federal do Paraná, Curitiba, 2001.

RACHWALL, M. F. G.; CURCIO, G. R.; DEDECEK, R. A.; NIETSCHE, K.; S FILHO, F. E. ; VOGEL, R. C. Influência da luminosidade sobre os teores de macronutrientes e tanino em folhas de erva-mate. . In: CONGRESSO SUL-AMERICANO DA ERVA-MATE, 2.; REUNIÃO TÉCNICA DA ERVAMATE, 3., Encantado, RS. Anais... Porto Alegre: Universidade Federal do Rio Grande do Sul. Fundação Estadual de Pesquisa Agropecuária, 2000. p. 417-420. 